PTK, Vol.2 No.1 2021

ISSN: 2747-1977 (Print) / 2747-1969 (Online)

DOI: https://doi.org/10.53624/ptk.v2i1.49

\title{
Video Interaktif sebagai Upaya Peningkatan Hasil Belajar Siswa Kelas V SDN Pucangsimo 1 Bandarkedungmulyo Jombang
}

\author{
Diterima: \\ 3 Januari 2021 \\ Revisi: \\ 26 Januari 2021 \\ Terbit: \\ 1 Februari 2021
}

\author{
Ervina Budi Lestari \\ SD Negeri Pucangsimo 1 Bandarkedungmulyo \\ Jombang, Indonesia \\ E-mail: elphiena@gmail.com
}

\begin{abstract}
Abstrak - Penggunaan media pembelajaran yang tepat merupakan faktor penunjang dalam keberhasilan proses pembelajaran, terutama pada pembelajaran daring. Berdasarkan observasi peneliti di SDN Pucangsimo 1 Bandarkedungmulyo Jombang. Dalam pembelajaran daring, guru masih menggunakan metode pembelajaran ceramah melalui whatsapp grup dan video call dengan mengacu pada referensi buku siswa. Hal ini memicu sering terjadinya miskonsepsi pada siswa, sehingga mengakibatkan rendahnya nilai hasil belajar siswa yang masih di bawah KKM. Oleh karena itu, diperlukan inovasi dalam pembelajaran, yaitu dengan penggunaan media video interaktif. Rancangan penelitian yang digunakan adalah penelitian tindakan kelas yang terdiri dari 2 siklus. Subjek penelitian ini adalah siswa kelas V SDN Pucangsimo 1 Bandarkedungmulyo Jombang yang berjumlah 33 siswa. Data penelitian diperoleh melalui observasi, tes, dan catatan lapangan. Data observasi kegiatan pembelajaran dianalisis dalam bentuk persentase dan nilai rata-rata kegiatan pembelajaran. Data tes hasil belajar siswa dianalisis dengan menjumlahkan nilai setiap aspek yang dinilai dan berdasarkan persentase ketuntasan belajar klasikal. Data catatan lapangan yang berisi berbagai kendala dianalisis kemudian dicari solusinya. Hasil penelitian menunjukkan bahwa hasil belajar siswa dalam pembelajaran mengalami peningkatan. Pada siklus I hasil belajar siswa mencapai $72,88 \%$ dan pada siklus II hasil belajar siswa mencapai $80,68 \%$. Kesimpulan yang dapat diambil dari penelitian ini adalah penggunaan video interaktif pada pembelajaran daring dapat meningkatkan hasil belajar siswa pada pembelajaran matematika materi pecahan di kelas V SDN Pucangsimo 1 Bandarkedungmulyo Jombang.
\end{abstract}

Kata Kunci- media pembelajaran, video interaktif, hasil belajar

\begin{abstract}
The use of appropriate learning media is a supporting factor in the success of the learning process, especially in online learning. Based on the observations of researchers at SDN Pucangsimo 1 Bandarkedungmulyo Jombang. In online learning, teachers still use the lecture learning method through whatsapp groups and video calls by referring to student book references. This triggers frequent misconceptions in students, resulting in low student learning outcomes that are still below the KKM. Therefore, innovation in learning is needed, namely the use of interactive video media. The research design used was classroom action research which consisted of 2 cycles. The subjects of this study were the fifth grade students of SDN Pucangsimo 1 Bandarkedungmulyo Jombang, totaling 33 students. Research data obtained through observation, tests, and field notes. Observation data of learning activities were analyzed in the form of percentages and the average value of learning activities. Data on student learning outcomes were analyzed by adding up the scores for each aspect assessed and based on the percentage of classical learning completeness. Field note data containing various obstacles were analyzed and then looked for solutions. The results showed that student learning outcomes in learning have increased. In the first cycle student learning outcomes reached $72.88 \%$ and in the second cycle student learning outcomes reached $80.68 \%$. The conclusion that can be drawn from this study is that the use of interactive videos in online learning can improve student learning outcomes in mathematics learning fractions in class V SDN Pucangsimo 1 Bandarkedungmulyo Jombang.
\end{abstract}

Keywords - learning media, interactive videos, learning outcomes 
ISSN: 2747-1977 (Print) / 2747-1969 (Online)

DOI: https://doi.org/10.53624/ptk.v2i1.49

\section{PENDAHULUAN}

Belajar adalah suatu proses perubahan tingkah laku akibat dari pengalaman (Darmuki 2020). Belajar merupakan suatu proses perubahan tingkah laku yang membutuhkan dorongan atau motivasi untuk menggerakkan ke arah lebih baik, dari tidak bisa menjadi bisa, dari tidak tahu menjadi tahu (Darmuki et al. 2017). Perubahan tingkah laku tersebut bisa berupa dari aspek kognitif, afektif, maupun psikomotorik (Hidayati et al. 2020). Belajar juga dapat didefinisikan sebuah proses dimana tingkah laku ditimbulkan/berubah melalui latihan dan pengalaman (Hariyadi and Darmuki 2019). Mengajar adalah menanamkan pengetahuan pada peserta didik untuk mencapai tujuan yang telah ditetapkan (Darmuki and Hidayati 2019). Kegiatan Belajar Mengajar (KBM) adalah suatu proses interaksi antara peserta didik dengan pendidik dan sumber belajar pada suatu lingkungan belajar (Darmuki et al. 2018). KBM merupakan bantuan yang diberikan pendidik agar dapat terjadi proses pemerolehan ilmu dan pengetahuan, penguasaan kemahiran dan tabiat, serta pembentukan sikap dan kepercayaan pada peserta didik sehingga peserta didik tumbuh dan berkembang dengan baik (Darmuki and Hidayati 2019). Hal ini sesuai dengan pernyataan Hidayati \& Darmuki (2021) yang mengemukakan bahwa KBM adalah suatu proses persiapan yang dipersiapkan oleh guru guna menarik dan memberi informasi kepada siswa, sehingga dengan persiapan yang dirancang oleh guru dapat membantu siswa dalam mencapai tujuan pembelajaran dengan maksimal. Tujuannya adalah penguasaan pengetahuan, keteterampilan dan pemahaman oleh peserta didik.

Pembelajaran matematika merupakan ilmu yang dipelajari dari tingkat sekolah dasar, sehingga pembelajaran matematika di Sekolah Dasar adalah pembelajaran yang membentuk konsep dasar yang ditanamkan kepada siswa sebagai bekal ilmu untuk pembelajaran berkelanjutan pada tingkat SMP dan SMA bahkan Perguruan Tinggi nantinya. Bahkan, matematika merupakan bidang keilmuan yang diterapkan pada semua bidang pekerjaan. Ruseffendi (Karso et al. 2009) menyatakan bahwa matematika itu terorganisasikan dari unsurunsur yang tidak didefinisikan, definisi-definisi, aksioma-aksioma, dan dalil-dalil, dimana dalildalil setelah dibuktikan kebenarannya berlaku secara umum, karena itulah matematika sering disebut ilmu deduktif. Pelajaran matematika masih dianggap sebagai salah satu mata pelajaran yang sulit dan pada umumnya siswa mempunyai anggap-an bahwa matematika merupakan pelajaran yang tidak disenangi. Matematika sering dianggap siswa sebagai salah satu mata pelajaran yang sulit, hal-hal negatif muncul pada diri siswa ketika belajar matematika, berupa alasan cemas. Sehingga, seorang guru perlu memahami berbagai karakter siswa dalam menerapkan metode maupun media pembelajaran yang akan digunakan pada pembelajaran matematika, terutama di tingkat sekolah dasar. 
PTK, Vol.2 No.1 2021

ISSN: 2747-1977 (Print) / 2747-1969 (Online)

DOI: https://doi.org/10.53624/ptk.v2i1.49

Salah satu standar kompetensi lulusan mata pelajaran matematika untuk satuan pendidikan dasar hingga menengah kurikulum 2006 menegaskan agar siswa memiliki kemampuan berpikir logis, analitis, sistematis, kritis dan kreatif serta kemampuan bekerjasama (Depdiknas 2006). Pelajaran Matematika membekali siswa dengan ilmu yang dapat diterapkan agar mampu mengatasi permasalahan yang muncul dalam kehidupan sehari-hari. Oleh karena itu, pelaksanaan pembelajaran Matematika tidak hanya memberikan informasi berupa teori atau konsep saja, melainkan juga berorientasi pada pengembangan keterampilan-keterampilan yang dibutuhkan dalam pemecahan masalah dalam kehidupan sehari-hari. Siswa perlu dibekali dengan keterampilan-keterampilan untuk menyelesaikan masalah karena pada hakikatnya belajar bukan hanya menghafal informasi akan tetapi suatu proses dalam pemecahan masalah (Azizah et al. 2018). Selain itu, Matematika akan menjadi pelajaran yang tidak bermakna bagi siswa bila mereka belum mampu mengimplementasikan konsep matematika ke dalam konteks kehidupan sehari-hari. Pembelajaran matematika dapat melatih siswa dalam berpikir kritis dan menalar. Berpikir kritis adalah berpikir yang reflektif secara mendalam dalam pengambilan keputusan dan pemecahan masalah untuk menganalisis situasi, mengevaluasi argumen, dan menarik kesimpulan yang tepat. Orang yang mampu berpikir kritis adalah orang yang mampu menyimpulkan apa yang diketahuinya, mengetahui cara menggunakan informasi untuk memecahkan permasalahan, dan mampu mencari sumber-sumber informasi yang relevan sebagai pendukung pemecahan masalah.

Dalam penerapan pembelajaran matematika di Sekolah Dasar, yang siswanya berada pada rentang usia 6-12 tahun, siswa mempelajari segala sesuatu secara konkret atau berdasarkan dengan pengalaman mereka sehari-hari. Bruner (Marisa et al. 2013) menyatakan bahwa pembelajaran sebaiknya dimulai dari pengalaman nyata dan dialami langsung oleh anak, meningkat kepada penggunaan gambar (visual) dan baru kemudian menggunakan unsur-unsur abstrak simbolis (kata-kata, tulisan). Oleh karena itu, penggunaan media pembelajaran yang tepat sangat berpengaruh terhadap penyampaian materi kepada siswa agar dapat tercapai tujuan pembelajaran yang diharapkan.

Pada masa pandemi covid-19, strategi pembelajaran harus diubah dari pembelajaran tatap muka menjadi pembelajaran dari rumah secara daring (dalam jaringan). Oleh karena itu, penggunaan media pembelajaran juga harus menyesuaikan dengan memanfaatkan berbagai perkembangan teknologi. Media pembelajaran yang diberikan tidak hanya dapat menyampaikan materi pembelajaran, tetapi juga yang dapat memotivasi belajar siswa. Penggunaan internet dan teknologi multimedia mampu merombak cara penyampaian pengetahuan dan dapat menjadi alternatif pembelajaran yang dilaksanakan dalam kelas (Zhang et al. 2004). Permasalahan yang muncul pada siswa kelas V SDN Pucangsimo 1 Bandarkedungmulyo Jombang, antara lain yaitu 
kurangnya minat belajar siswa pada pembelajaran matematika secara daring dan rendahnya hasil belajar siswa pada materi pecahan. Berdasarkan hal tersebut, maka peneliti menggunakan media video interaktif sebagai upaya peningkatan hasil belajar siswa kelas V SDN Pucangsimo 1 Bandarkedungmulyo Jombang.

\section{METODE}

Jenis penelitian yang dilaksanakan merupakan Penelitian Tindakan Kelas (PTK). PTK adalah penelitian tindakan yang dilakukan oleh guru di dalam kelasnya sendiri melalui refleksi diri, dengan tujuan untuk memperbaiki kinerjanya sebagai guru, sehingga hasil belajar siswa menjadi meningkat. Jadi, Penelitian Tindakan Kelas ini bertujuan untuk mengupayakan perbaikan pada kegiatan pembelajaran, sehingga dapat meningkatkan pengetahuan dan keterampilan, baik dalam hal proses maupun hasilnya. Tahapan-tahapan dalam penelitian ini adalah sebagai berikut: 1) Tahap penetapan isu/permasalahan, 2) perencanaan, 3) Tahap pelaksanaan, 4) Tahap observasi atau pengamatan, 5) Tahap kesimpulan dan refleksi. Kelima tahapan tersebut merupakan unsur-unsur yang membentuk sebuah siklus, yaitu satu putaran kegiatan yang berurutan (Arikunto 2010).

Data yang dikumpulkan meliputi, data validasi perangkat pembelajaran beserta instrumen penilaian, data pelaksanaan pembelajaran, data observasi atau pengamatan, serta dokumentasi kegiatan pembelajaran. Proses pembelajaran dilaksanakan secara daring (dalam jaringan) menggunakan pendekatan saintifik model Direct Instruction dan media pembelajaran video interaktif. Metode pembelajaran yang digunakan, yakni demonstrasi, pengamatan, diskusi, tanya jawab, dan penugasan. Pembelajaran meliputi mata pelajaran matematika pada materi pecahan kelas V. Proses pembelajaran dilaksanakan dalam 3 siklus, yakni pengamatan pada kemampuan awal siswa (pra siklus), pelaksanaan perbaikan pembelajaran pada siklus I, kemudian pelaksanaan pembelajaran pada siklus II. Pada setiap siklus dilaksanakan evaluasi pembelajaran di akhir kegiatan.

Pendekatan saintifik ditunjukkan dalam langkah-langkah kegiatan pembelajaran siswa, yakni kegiatan mengamati (observing), menanya (questioning), mengumpulkan informasi (experimenting), menalar (associating), dan mengkomunikasikan (communicating). Model pembelajaran Direct Instruction meliputi, 1) Menyampaikan tujuan dan mempersiapkan siswa, 2) Mempresentasikan dan mendemontrasikan pengetahuan atau keterampilan, 3) Membimbing pelatihan, 4) Mengecek pemahaman dan umpan balik, 5) Memberi kesempatan pelatihan lanjutan dan penerapan. Dalam penerapannya, siswa ditunjukkan benda-benda di sekitar untuk menstimulus pemahaman siswa mengenai konsep dasar pecahan, sehingga siswa dapat memahami hakikat dari pecahan. Kemudian siswa diberikan video interaktif agar siswa dapat 
PTK, Vol.2 No.1 2021

ISSN: 2747-1977 (Print) / 2747-1969 (Online)

DOI: https://doi.org/10.53624/ptk.v2i1.49

mengamati bagaimana teknik operasi hitung pecahan. Langkah-langkah pembelajaran yang dilakukan juga menerapkan adanya Critical Thinking, Creativity, Collaborative, dan Communicative.

Hasil evaluasi di setiap siklus akan diobservasi untuk mengetahui sejauh mana pemahaman siswa terhadap materi yang telah diberikan. Hasil peningkatan hasil belajar dari siklus sebelumnya didapatkan dari rata-rata nilai yang dibandingkan dengan rata-rata klasikal, sehingga diperoleh prosentase peningkatan hasil belajar siswa. Siswa yang belum mencapai Kriteria Ketuntasan Minimal (KKM) akan diberikan remedial, sedangkan siswa yang telah mencapai Kriteria Ketuntasan Minimal (KKM) akan diberikan tindak lanjut untuk mempersiapkan materi berikutnya.

\section{HASIL DAN PEMBAHASAN}

Penelitian ini dilaksanakan di SD Negeri Pucangsimo 1, yang merupakan salah satu SD Negeri yang beralamat di Desa Pucangsimo, Kecamatan Bandarkedungmulyo, Kabupaten Jombang. Berdiri pada tanggal 1 Maret 1924 memiliki luas tanah $1560 \mathrm{~m}^{2}$. Di atas tanah tersebut berdiri bangunan ruang kelas sebanyak 9 ruang, dilengkapi dengan ruang perpustakaan, ruang guru, ruang UKS, Mushola, Kantin sekolah, Green House, serta ruang pendukung lainnya. Untuk menunjang keberhasilan operasional SDN Pucangsimo 1 memiliki sumber daya manusia yang sudah berkualifikasi pendidikan SLTA dan S1. Tenaga operasional yang ada terdiri atas 1 orang Kepala Sekolah, Guru/Pendidik berjumlah 13 orang dan Tenaga Kependidikan berjumlah 1 orang.

Tabel 1. Data Tenaga Pendidik dan Kependidikan SDN Pucangsimo 1

\begin{tabular}{ccc} 
No. & Nama & Jabatan \\
\hline 1. & $(\mathrm{LS})$ & Kepala Sekolah \\
\hline 2. & $(\mathrm{IK})$ & Guru Kelas I-A \\
\hline 3. & $(\mathrm{~K})$ & Guru Kelas I-B \\
\hline 4. & $(\mathrm{COM})$ & Guru Kelas II-A \\
\hline 5. & $(\mathrm{NK})$ & Guru Kelas II-A \\
\hline 6. & $(\mathrm{~K})$ & Guru Kelas III \\
\hline 7. & $(\mathrm{SMS})$ & Guru Kelas IV \\
\hline 8. & $(\mathrm{EBL})$ & Guru Kelas V \\
\hline 9. & $(\mathrm{FS})$ & Guru Kelas VI-A \\
\hline 10. & $(\mathrm{~A})$ & Guru Kelas VI-B \\
\hline 11. & $(\mathrm{I})$ & Guru PAI \\
\hline 12. & $(\mathrm{AS})$ & Guru PJOK \\
\hline 13. & $(\mathrm{MJ})$ & Pembimbing Mulok Keagamaan \\
\hline 14. & $(\mathrm{ST}) \mathrm{KM}$ & Pembimbing Diniyah \\
\hline 15. & $(\mathrm{IM})$ & Penjaga Sekolah \\
\hline
\end{tabular}

Untuk mengetahui tingkat kemampuan awal siswa, diberikan pre tes pada pra siklus. Pre tes berupa tanya jawab singkat menggunakan media sedotan dan kertas yang dilakukan pada vcon 
PTK, Vol.2 No.1 2021

ISSN: 2747-1977 (Print) / 2747-1969 (Online)

DOI: https://doi.org/10.53624/ptk.v2i1.49

whatsapp berulang dengan setiap kelompok yang telah ditentukan. Hasil yang didapatkan, yakni sebagai berikut :

Tabel 2. Rekap Hasil Uji Kemampuan Awal Siswa

\begin{tabular}{|c|c|c|c|c|c|c|c|c|c|c|c|c|c|c|c|c|}
\hline \multirow{4}{*}{ No } & \multirow{4}{*}{ Nama Siswa } & \multicolumn{15}{|c|}{ PERTANYAAN } \\
\hline & & \multicolumn{3}{|c|}{1} & \multicolumn{3}{|c|}{2} & \multicolumn{3}{|c|}{3} & \multicolumn{3}{|c|}{4} & \multicolumn{3}{|c|}{5} \\
\hline & & \multicolumn{3}{|c|}{$\begin{array}{c}\text { Kertas yang } \\
\text { digunting } \\
\text { menjadi } 2 \text { bagian } \\
\text { sama besar }\end{array}$} & \multicolumn{3}{|c|}{$\begin{array}{c}\text { Kertas yang } \\
\text { digunting } \\
\text { menjadi } 4 \text { bagian } \\
\text { sama besar }\end{array}$} & \multicolumn{3}{|c|}{$\begin{array}{c}\text { Sedotan yang } \\
\text { digunting } \\
\text { menjadi } 2 \text { bagian } \\
\text { sama besar }\end{array}$} & \multicolumn{3}{|c|}{$\begin{array}{c}\text { Sedotan yang } \\
\text { digunting } \\
\text { menjadi } 3 \text { bagian } \\
\text { sama besar }\end{array}$} & \multicolumn{3}{|c|}{$\begin{array}{c}\text { Sedotan yang } \\
\text { digunting } \\
\text { menjadi } 4 \text { bagian } \\
\text { sama besar }\end{array}$} \\
\hline & & $\mathbf{B}$ & $\mathbf{S}$ & TM & $\mathbf{B}$ & $\mathbf{S}$ & TM & $\mathbf{B}$ & $\mathbf{S}$ & TM & B & $\mathbf{S}$ & TM & B & $\mathbf{S}$ & TM \\
\hline 1 & A D A. & & $\sqrt{ }$ & & $\sqrt{ }$ & & & $\sqrt{ }$ & & & & & $\sqrt{ }$ & & $\sqrt{ }$ & \\
\hline 2 & A M & $\sqrt{ }$ & & & & $\sqrt{ }$ & & $\sqrt{ }$ & & & & $\sqrt{ }$ & & & & $\sqrt{ }$ \\
\hline 3 & B P A & & & $\sqrt{ }$ & & & $\sqrt{ }$ & & $\sqrt{ }$ & & $\sqrt{ }$ & & & & $\sqrt{ }$ & \\
\hline 4 & $\mathrm{DO}$ & & $\sqrt{ }$ & & & $\sqrt{ }$ & & & & $\sqrt{ }$ & $\sqrt{ }$ & & & & $\sqrt{ }$ & \\
\hline 5 & D F & & & $\sqrt{ }$ & & & $\sqrt{ }$ & & $\sqrt{ }$ & & & & $\sqrt{ }$ & & & $\sqrt{ }$ \\
\hline 6 & F A R & & $\sqrt{ }$ & & $\sqrt{ }$ & & & & $\sqrt{ }$ & & $\sqrt{ }$ & & & & $\sqrt{ }$ & \\
\hline 7 & H R & $\sqrt{ }$ & & & $\sqrt{ }$ & & & $\sqrt{ }$ & & & & $\sqrt{ }$ & & & $\sqrt{ }$ & \\
\hline 8 & I L R. & $\sqrt{ }$ & & & $\sqrt{ }$ & & & & $\sqrt{ }$ & & $\sqrt{ }$ & & & & $\sqrt{ }$ & \\
\hline 9 & K P S & & $\sqrt{ }$ & & $\sqrt{ }$ & & & & $\sqrt{ }$ & & & $\sqrt{ }$ & & & & $\sqrt{ }$ \\
\hline 10 & L D K & & $\sqrt{ }$ & & & $\sqrt{ }$ & & $\sqrt{ }$ & & & & & $\sqrt{ }$ & & $\sqrt{ }$ & \\
\hline 11 & M Y Fe A & & $\sqrt{ }$ & & & & $\sqrt{ }$ & $\sqrt{ }$ & & & & & $\sqrt{ }$ & & $\sqrt{ }$ & \\
\hline 12 & M A P & & $\sqrt{ }$ & & & & $\sqrt{ }$ & & & $\sqrt{ }$ & & & $\sqrt{ }$ & & & $\sqrt{ }$ \\
\hline 13 & M IR & $\sqrt{ }$ & & & & $\sqrt{ }$ & & $\sqrt{ }$ & & $\sqrt{ }$ & & & $\sqrt{ }$ & & & $\sqrt{ }$ \\
\hline 14 & M A F. & $\sqrt{ }$ & & & & $\sqrt{ }$ & & & $\sqrt{ }$ & & & & $\sqrt{ }$ & & $\sqrt{ }$ & \\
\hline 15 & M A J. & $\sqrt{ }$ & & & & $\sqrt{ }$ & & & $\sqrt{ }$ & & & & $\sqrt{ }$ & & $\sqrt{ }$ & \\
\hline 16 & M A & & $\sqrt{ }$ & & & $\sqrt{ }$ & & & $\sqrt{ }$ & & & & $\sqrt{ }$ & & & $\sqrt{ }$ \\
\hline 17 & M A W. & $\sqrt{ }$ & & & $\sqrt{ }$ & & & $\sqrt{ }$ & & & & $\sqrt{ }$ & & & $\sqrt{ }$ & \\
\hline 18 & M F R & & & $\sqrt{ }$ & & & $\sqrt{ }$ & & & $\sqrt{ }$ & & & $\sqrt{ }$ & & & $\sqrt{ }$ \\
\hline 19 & M G R & & $\sqrt{ }$ & & & $\sqrt{ }$ & & & $\sqrt{ }$ & & & & $\sqrt{ }$ & & & $\sqrt{ }$ \\
\hline 20 & $\mathrm{MN}$ & & & $\sqrt{ }$ & & $\sqrt{ }$ & & & $\sqrt{ }$ & & & & $\sqrt{ }$ & & $\sqrt{ }$ & \\
\hline 21 & M R & $\sqrt{ }$ & & & $\sqrt{ }$ & & & & $\sqrt{ }$ & & & $\sqrt{ }$ & & & $\sqrt{ }$ & \\
\hline 22 & M F. & & & $\sqrt{ }$ & & & $\sqrt{ }$ & & $\sqrt{ }$ & & & $\sqrt{ }$ & & & & $\sqrt{ }$ \\
\hline 23 & N E P & & $\sqrt{ }$ & & & $\sqrt{ }$ & & $\sqrt{ }$ & & & & & $\sqrt{ }$ & & & $\sqrt{ }$ \\
\hline 24 & $\mathrm{~N} \mathrm{~S}$ & & $\sqrt{ }$ & & & & $\sqrt{ }$ & & & $\sqrt{ }$ & & & $\sqrt{ }$ & & & $\sqrt{ }$ \\
\hline 25 & N A Y & & $\sqrt{ }$ & & & $\sqrt{ }$ & & $\sqrt{ }$ & & & & & $\sqrt{ }$ & & & $\sqrt{ }$ \\
\hline 26 & O L S. & & $\sqrt{ }$ & & & & $\sqrt{ }$ & & & $\sqrt{ }$ & & & $\sqrt{ }$ & & & $\sqrt{ }$ \\
\hline 27 & R P P. & & $\sqrt{ }$ & & & & $\sqrt{ }$ & & $\sqrt{ }$ & & & & $\sqrt{ }$ & & & $\sqrt{ }$ \\
\hline 28 & $\mathrm{RA} \mathrm{A}$ & $\sqrt{ }$ & & & & $\sqrt{ }$ & & & $\sqrt{ }$ & & & & $\sqrt{ }$ & & $\sqrt{ }$ & \\
\hline 29 & R A & & $\sqrt{ }$ & & & & $\sqrt{ }$ & & & $\sqrt{ }$ & & & $\sqrt{ }$ & & & $\sqrt{ }$ \\
\hline 30 & S DSO & & $\sqrt{ }$ & & & $\sqrt{ }$ & & $\sqrt{ }$ & & & & $\sqrt{ }$ & & & & $\sqrt{ }$ \\
\hline 31 & $\mathrm{~S} A \mathrm{~S}$ & & $\sqrt{ }$ & & $\sqrt{ }$ & & & & & $\sqrt{ }$ & & & $\sqrt{ }$ & & $\sqrt{ }$ & \\
\hline 32 & S F & & $\sqrt{ }$ & & & & $\sqrt{ }$ & & $\sqrt{ }$ & & & & $\sqrt{ }$ & & & $\sqrt{ }$ \\
\hline 33 & UN R & & $\sqrt{ }$ & & & $\sqrt{ }$ & & $\sqrt{ }$ & & & & $\sqrt{ }$ & & & & $\sqrt{ }$ \\
\hline
\end{tabular}


PTK, Vol.2 No.1 2021

ISSN: 2747-1977 (Print) / 2747-1969 (Online)

DOI: https://doi.org/10.53624/ptk.v2i1.49

Keterangan :

$\mathrm{B}=$ Jawaban Benar

$\mathrm{S}=$ Jawaban Salah

$\mathrm{TM}=$ Tidak Menjawab

Berdasarkan Rekap Hasil Uji Kemampuan Awal pada pra siklus dapat diketahui bahwa tingkat pemahaman materi pecahan pada siswa masih rendah, yakni 19,39\%. Oleh karena itu, diperlukan adanya inovasi pembelajaran sebagai perbaikan yang dilaksanakan pada siklus I. Berdasarkan rekap hasil evaluasi pembelajaran pada siklus I, didapatkan hasil belajar siswa meningkat menjadi 72,88\%, seperti pada tabel 3 berikut:

Tabel 3. Rekap hasil evaluasi siklus I

\begin{tabular}{|c|c|c|c|c|c|c|c|}
\hline \multirow[b]{2}{*}{ No } & \multirow[b]{2}{*}{ Nama Siswa } & \multicolumn{3}{|c|}{ KRITERIA I } & \multicolumn{3}{|c|}{ KRITERIA II } \\
\hline & & Benar & Salah & $\begin{array}{c}\text { Tidak } \\
\text { Menjawab }\end{array}$ & Benar & Salah & $\begin{array}{c}\text { Tidak } \\
\text { Menjawab }\end{array}$ \\
\hline 1 & A D A. & 6 & 2 & 0 & 4 & 1 & 0 \\
\hline 2 & $\mathrm{AM}$ & 7 & 1 & 0 & 5 & 0 & 0 \\
\hline 3 & B P A & 5 & 2 & 1 & 3 & 2 & 0 \\
\hline 4 & $\mathrm{DO}$ & 5 & 3 & 0 & 4 & 1 & 0 \\
\hline 5 & $\mathrm{DF}$ & 4 & 3 & 1 & 3 & 2 & 0 \\
\hline 6 & F A R & 6 & 2 & 0 & 5 & 0 & 0 \\
\hline 7 & H R & 8 & 0 & 0 & 5 & 0 & 0 \\
\hline 8 & I L R. & 8 & 0 & 0 & 5 & 0 & 0 \\
\hline 9 & K P S & 7 & 1 & 0 & 5 & 0 & 0 \\
\hline 10 & L D K & 6 & 1 & 1 & 4 & 1 & 0 \\
\hline 11 & M Y Fe A & 5 & 2 & 1 & 4 & 1 & 0 \\
\hline 12 & M A P & 3 & 3 & 2 & 2 & 2 & 1 \\
\hline 13 & M IR & 6 & 1 & 1 & 4 & 1 & 0 \\
\hline 14 & M A F. & 5 & 1 & 2 & 3 & 2 & 0 \\
\hline 15 & M A J. & 6 & 2 & 0 & 3 & 2 & 0 \\
\hline 16 & $\mathrm{M} \mathrm{A}$ & 6 & 2 & 0 & 3 & 2 & 0 \\
\hline 17 & M A W. & 8 & 0 & 0 & 5 & 0 & 0 \\
\hline 18 & MFR & 3 & 3 & 2 & 2 & 2 & 1 \\
\hline 19 & M G R & 4 & 3 & 1 & 3 & 2 & 0 \\
\hline 20 & M N & 6 & 2 & 0 & 4 & 1 & 0 \\
\hline 21 & M R & 7 & 1 & 0 & 5 & 0 & 0 \\
\hline 22 & MF. & 5 & 1 & 2 & 2 & 2 & 1 \\
\hline 23 & NEP & 6 & 2 & 0 & 4 & 1 & 0 \\
\hline 24 & $\mathrm{NS}$ & 5 & 3 & 0 & 3 & 2 & 0 \\
\hline 25 & N A Y & 6 & 2 & 0 & 4 & 1 & 0 \\
\hline 26 & O L S. & 5 & 2 & 1 & 3 & 2 & 0 \\
\hline 27 & R P P. & 4 & 2 & 2 & 3 & 2 & 0 \\
\hline 28 & R A W & 6 & 2 & 0 & 4 & 1 & 0 \\
\hline 29 & R A & 5 & 2 & 1 & 3 & 2 & 0 \\
\hline 30 & S DSO & 6 & 1 & 1 & 4 & 1 & 0 \\
\hline 31 & S A S & 6 & 2 & 0 & 4 & 1 & 0 \\
\hline 32 & S F & 6 & 1 & 1 & 4 & 1 & 0 \\
\hline 33 & UN R & 7 & 1 & 0 & 4 & 1 & 0 \\
\hline & Jumlah & 188 & 56 & 20 & 123 & 39 & 3 \\
\hline & Prosentase & $71,21 \%$ & $21,21 \%$ & $7,58 \%$ & $74,55 \%$ & $23,64 \%$ & $1,82 \%$ \\
\hline
\end{tabular}


Prosentase peningkatan pada siklus I diperoleh dari rata-rata prosentase pada kriteria I dan kriteria II, sehingga didapatkan hasil belajar siswa meningkat menjadi $72,88 \%$. Berdasarkan perbandingan pada hasil belajar yang didapatkan pada siklus I, didapatkan hasil belajar pada siklus II meningkat menjadi 80,68\% seperti data pada tabel 4 .

Tabel 4. Rekap hasil evaluasi siklus II

\begin{tabular}{|c|c|c|c|c|}
\hline \multirow[b]{2}{*}{ No } & \multirow[b]{2}{*}{ Nama Siswa } & \multicolumn{3}{|c|}{ KRITERIA } \\
\hline & & Benar & Salah & $\begin{array}{c}\text { Tidak } \\
\text { Menjawab }\end{array}$ \\
\hline 1 & A D A. & 8 & 0 & 0 \\
\hline 2 & A M & 8 & 0 & 0 \\
\hline 3 & B P A & 6 & 2 & 0 \\
\hline 4 & $\mathrm{DO}$ & 8 & 0 & 0 \\
\hline 5 & D F & 5 & 3 & 0 \\
\hline 6 & F A R & 8 & 0 & 0 \\
\hline 7 & H R & 8 & 0 & 0 \\
\hline 8 & I L R. & 8 & 0 & 0 \\
\hline 9 & K P S & 8 & 0 & 0 \\
\hline 10 & L D K & 8 & 0 & 0 \\
\hline 11 & M Y Fe A & 6 & 2 & 0 \\
\hline 12 & M A P & 4 & 4 & 0 \\
\hline 13 & M IR & 8 & 0 & 0 \\
\hline 14 & M A F. & 6 & 2 & 0 \\
\hline 15 & M A J. & 6 & 2 & 0 \\
\hline 16 & $\mathrm{M} \mathrm{A}$ & 6 & 2 & 0 \\
\hline 17 & M A W. & 8 & 0 & 0 \\
\hline 18 & M F R & 4 & 4 & 0 \\
\hline 19 & M G R & 5 & 3 & 0 \\
\hline 20 & $\mathrm{MN}$ & 6 & 2 & 0 \\
\hline 21 & M R & 8 & 0 & 0 \\
\hline 22 & M F. & 4 & 4 & 0 \\
\hline 23 & N E P & 7 & 1 & 0 \\
\hline 24 & N S & 6 & 2 & 0 \\
\hline 25 & N A Y & 6 & 2 & 0 \\
\hline 26 & O L S. & 5 & 3 & 0 \\
\hline 27 & R P P. & 5 & 3 & 0 \\
\hline 28 & R A W & 7 & 1 & 0 \\
\hline 29 & $\mathrm{R} A$ & 5 & 3 & 0 \\
\hline 30 & S DSO & 7 & 1 & 0 \\
\hline 31 & $\mathrm{~S} A \mathrm{~S}$ & 6 & 2 & 0 \\
\hline 32 & $\mathrm{~S} \mathrm{~F}$ & 6 & 2 & 0 \\
\hline 33 & UN R & 7 & 1 & 0 \\
\hline & Jumlah & 213 & 51 & $\mathbf{0}$ \\
\hline & Prosentase & $80,68 \%$ & $19,32 \%$ & $0,00 \%$ \\
\hline
\end{tabular}

Berikut ini perbandingan nilai ketuntasan belajar siswa secara klasikal yang terjadi pada siklus I dan II. Pada siklus I masih terdapat siswa yang tidak berhasil menjawab pertanyaan, sedangkan pada siklus II semua siswa sudah mampu menjawab pertanyaan yang diberikan. 
PTK, Vol.2 No.1 2021

ISSN: 2747-1977 (Print) / 2747-1969 (Online)

DOI: https://doi.org/10.53624/ptk.v2i1.49

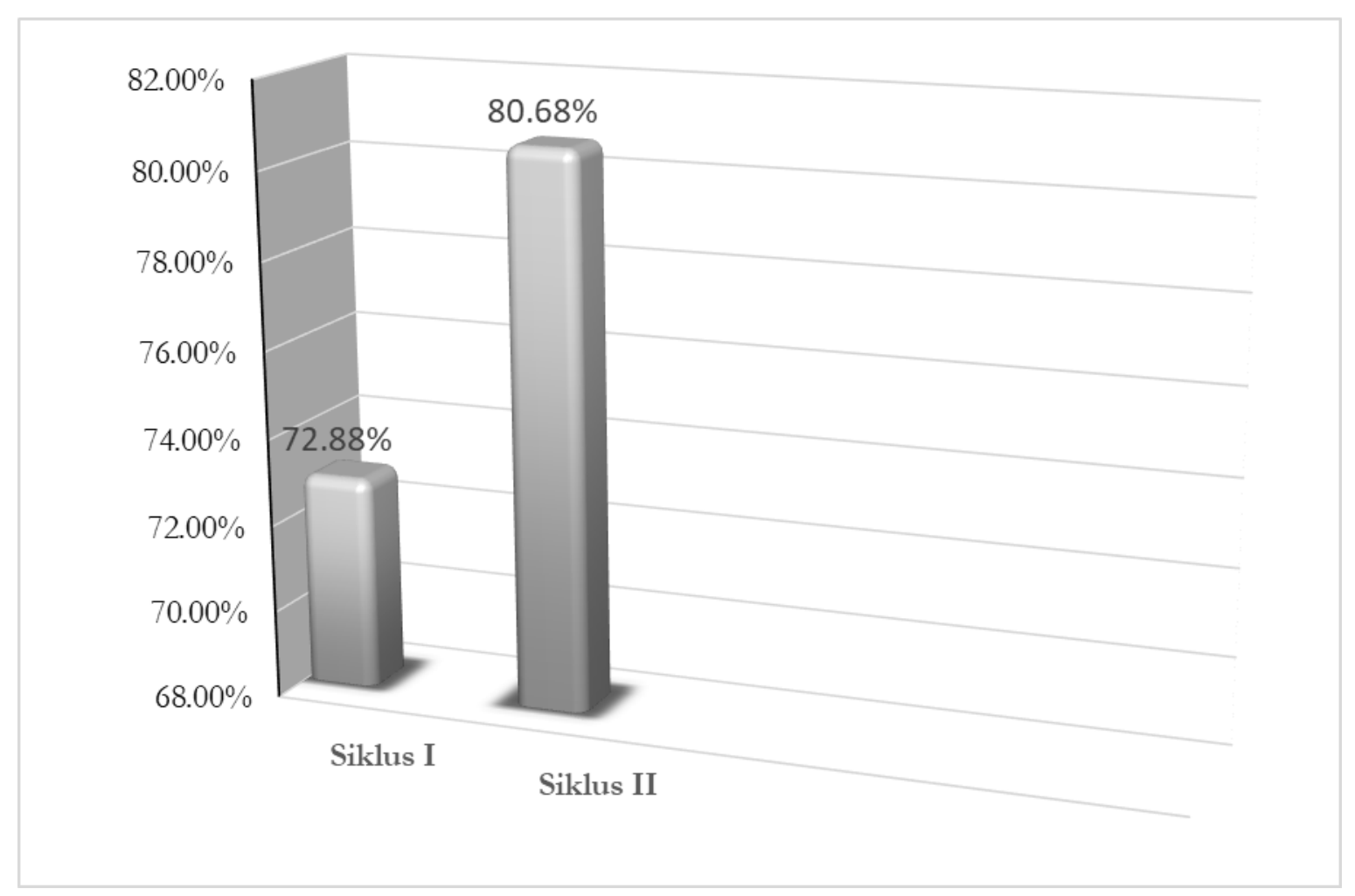

Gambar 1. Perbandingan Siklus I dan II

\section{KESIMPULAN}

Pembelajaran dari rumah secara daring merupakan solusi dalam masa pandemi covid-19. Kegiatan Penelitian Tindakan Kelas ini dilaksanakan pada pembelajaran daring secara sinkronus dan asinkronus. Kegiatan pembelajaran menggunakan inovasi media pembelajaran video interaktif pada materi pecahan. Berdasarkan hasil pembelajaran yang telah dilakukan, dapat disimpulkan bahwa hasil belajar materi pecahan pada siswa kelas V SDN Pucangsimo 1 Kecamatan Bandarkedungmulyo Kabupaten Jombang mengalami peningkatan. Pada tahap uji kemampuan awal, yaitu tahap pra siklus didapatkan data hasil belajar siswa yang masih rendah yaitu 19,39\%. Kemudian pada pembelajaran siklus I, hasil belajar siswa meningkat menjadi 72,88\%. Pada pembelajaran siklus II, hasil belajar siswa meningkat menjadi 80,68\%.

\section{DAFTAR PUSTAKA}

Arikunto, Suharsimi. 2010. Prosedur Suatu Pendekatan Praktik. Jakarta: Rineka Cipta.

Azizah, dkk. 2018. Analisis Keterampilan Berpikir Kritis Siswa Sekolah Dasar Pada Pembelajaran Matematika Kurikulum 2013. Jurnal Pendidikan. Vol. 35 (1) : 61.

Darmuki, A. \& Hidayati N.A. 2019. An Investigation of The Cooperative Learning Using 
Audio Visual Media in Speaking Skill Subject. ICSTI. 121-126.

Darmuki, A., Ahmad Hariyadi, Nur Alfin Hidayati. 2020. Peningkatan Minat dan Hasil Belajar Keterampilan Berbicara Menggunakan Metode Mind Map pada Mahasiswa Kelas IA PBSI IKIP PGRI Bojonegoro Tahun Akademik 2019/2020. Kredo.

Darmuki, A., Andayani, Joko Nurkamto, Kundharu Saddhono. 2017. Evaluating InformationProcessing-Based Learning Cooperative Model on Speaking Skill Course. Journal of Language Teaching and Reasearch. 8(1) pp. 44-51.

Darmuki, A., Andayani, Joko Nurkamto, Kundharu Saddhono. (2018). The Development and Evaluation of Speaking Learning Model by Cooperative Approach. International Journal of Instruction. 11(2), 115-128.

Darmuki, Agus. 2020. Upaya Meningkatkan Kemampuan Berbicara Mahasiswa Menggunakan Media Aplikasi Google Meet Berbasis Unggah Tugas Video Di Youtube Pada Masa Pandemi Covid-19. Jurnal Educatio FKIP UNMA, Vol 6(2),655-661

Depdiknas. 2006. Kurikulum Tingkat Satuan Pendidikan SD/MI. Jakarta: Depdiknas.

Hariyadi, A and Darmuki, A. 2019. Eksperimentasi Model Pembelajaran Jucama Ditinjau Dari Gaya Belajar Terhadap Prestasi Belajar Mahasiswa Mata Kuliah Berbicara Di Prodi PBSI IKIP PGRI Bojonegoro. Kredo. 3(1), 62-72.

Hariyadi, A., Agus Darmuki. 2019. Prestasi dan Motivasi Belajar dengan Konsep Diri. Prosiding Seminar Nasional Penguatan Muatan Lokal Bahasa Daerah sebagai Pondasi Pendidikan Karakter Generasi Milenial. PGSD UMK 2019, 280-286.

Hidayati, N. A., \& Darmuki, A. 2021. Penerapan Model Auditory Intellectually Repetition (AIR) untuk Meningkatkan Kemampuan Berbicara Pada Mahasiswa . Jurnal Educatio FKIP UNMA, 7(1), 252-259.

Karso, et al. (2009). Pendidikan Matematika I. Jakarta: Universitas Terbuka.

Marisa, et al. 2013. Komputer dan Media Pembelajaran. Tangerang Selatan: Universitas Terbuka.

Zhang, et al. 2004. Can e-learning replace classroom learning? Communications of the ACM.Vol. 47 No.5. 